\title{
Health Benefits and Cost-Effectiveness of Asymptomatic Screening for Hypertension and High Cholesterol and Aspirin Counseling for Primary Prevention
}

\author{
Steven P. Debmer, PbD \\ Michael V. Maciosek, PbD \\ Amy B. LaFrance, MPH \\ Thomas J. Flottemesch, PbD \\ HealthPartners Institute, Minneapolis, Minnesota
}

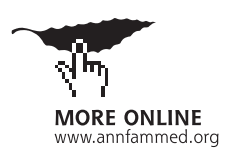

Conflicts of interest: authors report none.

\section{CORRESPONDING AUTHOR}

Steven P. Dehmer, PhD HealthPartners Institute Mail stop 23301A

PO Box 1524

Minneapolis, MN 55440-1524

steven.p.dehmer@healthpartners.com.

\begin{abstract}
PURPOSE Our aim was to update estimates of the health and economic impact of clinical services recommended for the primary prevention of cardiovascular disease (CVD) for the comparative rankings of the National Commission on Prevention Priorities, and to explore differences in outcomes by sex and race/ethnicity.

METHODS We used a single, integrated, microsimulation model to generate comparable results for 3 services recommended by the US Preventive Services Task Force: aspirin counseling for the primary prevention of CVD and colorectal cancer, screening and treatment for lipid disorders (usually high cholesterol), and screening and treatment for hypertension. Analyses compare lifetime outcomes from the societal perspective for a US-representative birth cohort of 100,000 persons with and without access to each clinical preventive service. Primary outcomes are health impact, measured by the net difference in lifetime qualityadjusted life years (QALYS), and cost-effectiveness, measured in incremental cost per QALY or cost savings per person in 2012 dollars. Results are also presented for population subgroups defined by sex and race/ethnicity.
\end{abstract}

RESULTS Health impact is highest for hypertension screening and treatment $(15,600$ QALYs), but is closely followed by cholesterol screening and treatment $(14,300$ QALYs). Aspirin counseling has a lower health impact (2,200 QALYs) but is found to be cost saving ( $\$ 31$ saved per person). Cost-effectiveness for cholesterol and hypertension screening and treatment is $\$ 33,800$ per QALY and $\$ 48,500$ per QALY, respectively. Findings favor hypertension over cholesterol screening and treatment for women, and opportunities to reduce disease burden across all services are greatest for the non-Hispanic black population.

CONCLUSIONS All 3 CVD preventive services continue to rank highly among other recommended preventive services for US adults, but individual priorities can be tailored in practice by taking a patient's demographic characteristics and clinical objectives into account.

Ann Fam Med 2017;15:23-36. https://doi.org/10.1370/afm.2015

\section{INTRODUCTION}

I n 1950 the rate of mortality from cardiovascular disease (CVD) in the United States was more than twice what it is today. ${ }^{1}$ Some of this reduction is attributable to new technologies and improvements in the treatment of CVD, but as much as one-half is due to prevention efforts. ${ }^{2} \mathrm{Nev}$ ertheless, CVD remains the leading cause of death and among the greatest causes of morbidity in the United States today. ${ }^{3,4}$ Each year, more than 1.2 million first-time CVD events are suffered, and persons younger than 75 years will die of a cardiovascular-related cause at approximately twice the rate of leading nations-a statistic that ranks 23 rd among major countries. ${ }^{5}$ Total direct and indirect costs of CVD are estimated to exceed $\$ 300$ billion annually, and total direct medical costs are projected to triple by 2030, when more than $40 \%$ of the US population is projected to have some form of CVD. ${ }^{5,6}$ Indeed, despite prior successes, only a small percentage of the 
US population meets criteria for ideal cardiovascular health ${ }^{7}$ cholesterol and blood pressure management remain major sources of preventable burden, ${ }^{8}$ and sizable persisting disparities in CVD outcomes based on sex, race/ethnicity, and geography can be explained by disparities in cardiometabolic risk factors. ${ }^{9,10}$

Although the case for sustained and improved CVD prevention efforts would appear to be strong, a core focus of the National Commission on Prevention Priorities has been to evaluate and identify the relative value of primary prevention activities in the context of a wide spectrum of health conditions and diseases. ${ }^{11}$ In 2006 the commission ranked using aspirin for the primary prevention of CVD, screening for lipid disorders, and hypertension screening-all 3 recommended with an A or B grade by the US Preventive Services Task Force (USPSTF) $)^{12-14}$-in the top one-half of clinical preventive services as measured by population health impact and cost-effectiveness. ${ }^{15}$ All 3 recommendations have since been updated by the USPSTF, ${ }_{1}^{16-18}$ pharmacy costs of treating cholesterol and blood pressure have seen sustained declines, ${ }_{1}^{19,20}$ the Million Hearts initiative has been introduced ${ }^{21}$ and CVD risk factor trends have continued to gradually evolve..$^{22,23}$

In this study, we use microsimulation modeling to estimate the health impact and cost-effectiveness of these leading CVD clinical preventive services for an updated ranking ${ }^{24}$ and provide new data on the relative impact of these services among population subgroups defined by sex and race/ethnicity. Adequate understanding of the relative priority of these services in busy primary care offices requires updated estimates that reflect changes in population disease-risk profiles, costs, and the evidence base supporting the services. In addition, physicians who seek to tailor priorities to the demographics of their clinical practice or to individual patients need to understand the value of these services for specific population groups.

\section{METHODS}

Analyses in this study were conducted using the HealthPartners Institute ModelHealth ${ }^{\mathrm{TM}}$ : Cardiovascular Disease (ModelHealth: CVD) microsimulation model. Brief descriptions of how the preventive services are implemented in the model and the model itself are described below, and comprehensive details of our methods are provided in the Supplemental Appendix, available at http://www.annfammed.org/content/15/1/23/suppl/DC1.

\section{Aspirin Counseling to Prevent Cardiovascular Disease and Cancer}

The USPSTF has substantially revised its recommendations regarding aspirin counseling for the primary prevention of CVD and colorectal cancer. ${ }^{16,25,26}$ The Task Force now recommends use of low-dose aspirin among men and women aged 50 to 59 years with $10 \%$ or greater 10-year CVD risk (B recommendation). With its updated evidence review, aspirin is found to reduce the risk of nonfatal myocardial infarction and ischemic stroke-no longer differing by sex-and to lower the risk of colorectal cancer incidence after 10 years of use (Table 1). The USPSTF review also reaffirmed aspirin's role in increasing risk for major gastrointestinal bleeding and hemorrhagic stroke.

For our analysis, the proportion of persons for whom aspirin use is consistent with the new USPSTF recommendation was estimated using data from the National Health Interview Survey. ${ }^{51}$ The per incident cost of CVD risk assessment and discussion regarding aspirin use is estimated to be $\$ 29.23$, and the cost of a year's supply of low-dose aspirin is estimated to be $\$ 18.23$. We assume that a clinical screening test and discussion may occur up to 3 times between ages 50 to 59 years.

\section{Cholesterol Screening}

In 2008 the USPSTF updated its 2001 recommendation for lipid disorder screening among adults aged 20 years and older. ${ }^{13,17}$ The Task Force found good evidence that drug therapy can significantly lower heart disease risk in persons with abnormal lipid levels. ${ }^{59}$ The USPSTF recommends screening men aged 35 years and older for lipid disorders regardless of risk factors (A recommendation) and men aged 20 to 35 years (B recommendation) if they are at increased risk for heart disease. For women, the Task Force recommends screening those aged 45 years and older $(\mathrm{A}$ recommendation) and those aged 20 to 45 years ( $B$ recommendation), in both cases, when at increased risk for heart disease. Upon detection of lipid disorders, standard treatment and management guidelines should be followed. ${ }^{17,61}$

For our analysis, the proportion of persons treating high cholesterol levels with medications as prescribed was estimated using data from the National Health and Nutrition Examination Survey (NHANES) (Table 1). ${ }^{52}$ ${ }^{56}$ The efficacy of medications for treating lipid disorders was estimated using data from large randomized controlled trials. ${ }^{33-41}$ The per incident cost of clinical screening and discussion regarding statin use is estimated to be $\$ 55.56$, and the annual medication cost is estimated to be $\$ 528.00$. We assume that a cholesterol screening test may occur up to once every 5 years.

\section{Hypertension Screening}

In 2007 the USPSTF published a reaffirmation of its 2003 A recommendation to screen for hypertension among all adults aged 18 years and older. ${ }^{14,18}$ The Task 
Table 1. Key Model Parameters

\begin{tabular}{|c|c|c|c|}
\hline Parameter & Value & $\begin{array}{l}\text { Sensitivity } \\
\text { Range }^{a}\end{array}$ & Source \\
\hline \multicolumn{4}{|l|}{$\begin{array}{l}\text { Aspirin for primary prevention of CVD } \\
\text { and colorectal cancer }\end{array}$} \\
\hline Colorectal cancer incidence $>10 \mathrm{y}, \mathrm{RR}$ & 0.60 & $0.76 / 0.47$ & Chubak $^{27,28}$ \\
\hline Cardiovascular disease death, RR & 1.00 & $1.00 / 0.97$ & Guirguis-Blake 29,30 \\
\hline Gastrointestinal bleed, RR & 1.58 & $1.95 / 1.29$ & Whitlock ${ }^{31,32}$ \\
\hline Hemorrhagic stroke, RR & 1.27 & $1.68 / 1.00$ & Whitlock 31,32 \\
\hline Ischemic stroke, nonfatal, RR & 0.86 & $0.98 / 0.76$ & Guirguis-Blake 29,30 \\
\hline Myocardial infarction, nonfatal, RR & 0.83 & $0.94 / 0.74$ & Guirguis-Blake 29,30 \\
\hline Cost per screening, $\$$ & 29.23 & $\pm 25 \%$ & See text \\
\hline Treatment cost, annual, $\$$ & 18.23 & $\pm 25 \%$ & See text \\
\hline \multicolumn{4}{|l|}{ Cholesterol screening } \\
\hline $\begin{array}{l}\text { High-density lipoprotein, median treatment } \\
\text { efficacy, mg/dL }\end{array}$ & +1.6 & Not considered & $\begin{array}{c}\text { 4S, }{ }^{33} \text { Downs, }^{34} \text { Holdaas, }^{32} \text { Sever, } 33 \text { Knopp }^{37} \\
\text { MRC/BHF, }{ }^{38} \text { LIPID, }^{39} \text { Shepherd }^{40,41}\end{array}$ \\
\hline $\begin{array}{l}\text { Low-density lipoprotein, median treatment } \\
\text { efficacy, mg/dL }\end{array}$ & -49.9 & Not considered & $\begin{array}{c}\text { 4S, }{ }^{33} \text { Downs, }^{34} \text { Holdaas, }^{32} \text { Sever, } 33 \text { Knopp, } \\
\text { MRC/BHF, }{ }^{38} \text { LIPID, }^{39} \text { Shepherd }^{40,41}\end{array}$ \\
\hline Cost per screening, $\$$ & 55.56 & $\pm 25 \%$ & See text \\
\hline Treatment and management cost, annual, $\$$ & 528.00 & $\pm 25 \%$ & See text \\
\hline \multicolumn{4}{|l|}{ Hypertension screening } \\
\hline $\begin{array}{l}\text { Systolic blood pressure, median treatment } \\
\text { efficacy, mm Hg }\end{array}$ & -6.5 & Not considered & 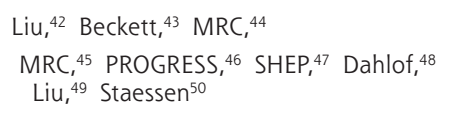 \\
\hline Cost per screening, $\$$ & 29.23 & $\pm 25 \%$ & See text \\
\hline Treatment and management annual cost, $\$$ & 278.52 & $\pm 25 \%$ & See text \\
\hline \multicolumn{4}{|l|}{ All services } \\
\hline $\begin{array}{l}\text { Aspirin use rate, primary/ } \\
\text { secondary prevention, \% }\end{array}$ & $77 / 86$ & $\pm 10 \%$ points & NHIS 51 \\
\hline \multicolumn{4}{|l|}{$\begin{array}{l}\text { Blood pressure and lipid medication use } \\
\text { rates, primary/secondary prevention, \% }\end{array}$} \\
\hline Age $18-39$ y & $62 / 77$ & $\pm 10 \%$ points & NHANES $52-56$ \\
\hline Age $40-64$ y & $84 / 89$ & $\pm 10 \%$ points & NHANES $52-56$ \\
\hline Age $>65 y$ & $94 / 97$ & $\pm 10 \%$ points & NHANES $52-56$ \\
\hline Myocardial infarction cost, 1st y/ongoing, $\$$ & $37,095 / 2,490$ & $\pm 25 \%$ & AHRQ/MEPS 57 \\
\hline $\begin{array}{l}\text { Myocardial infarction QALY decrement, } \\
\text { 1st y/ongoing }\end{array}$ & $0.3(3 \mathrm{mo}) / 0.0$ & $\pm 0.1 \mathrm{QALY}$ & Maciosek ${ }^{58}$ \\
\hline Screening and counseling acceptance rate, $\%$ & 90 & $\pm 10 \%$ points & Assumed \\
\hline Stroke cost, 1st y/ongoing, $\$$ & $18,192 / 5,389$ & $\pm 25 \%$ & AHRQ/MEPS 57 \\
\hline Stroke QALY decrement, 1st y/ongoing & $0.4 / 0.4$ & $\pm 0.1 \mathrm{QALY}$ & Maciosek $^{58}$ \\
\hline Treatment effectiveness, \% & 70 & $\pm 10 \%$ points & Calibrated assumption \\
\hline \multicolumn{4}{|c|}{$\begin{array}{l}\text { 4S = Scandinavian Simvastatin Survival Study; AHRQ = Agency for Healthcare Research and Quality; CVD = cardiovascular disease; MEPS = Medical Expenditure Panel } \\
\text { Survey; NCEP = National Cholesterol Education Program; NCHS = National Center for Health Statistics; NHANES = National Health and Nutrition Examination Survey; } \\
\text { QALY = quality-adjusted life years; RR = relative risk; SHEP = Systolic Hypertension in the Elderly Program. }\end{array}$} \\
\hline \multicolumn{4}{|c|}{ a The sensivity range indicates the lower and upper bounds (ie, worst case/best case) used in the deterministic sensitivity analysis. } \\
\hline
\end{tabular}

Force found good evidence that treatment of high blood pressure in adults can substantially decrease risk of cardiovascular disease. ${ }^{61}$ Upon detection of high blood pressure, standard treatment and management guidelines should be followed. ${ }^{18,62}$

For our analysis, the proportion of persons treating blood pressure with medications as prescribed was estimated using data from NHANES (Table 1). ${ }^{52-56}$ The efficacy of medications for treating hypertension was estimated from large randomized controlled trials. ${ }^{42-50}$ The per incident cost of a blood pressure screen for hypertension is estimated to be $\$ 29.23$, and the annual medication cost is estimated to be $\$ 278.52$. We assume blood pressure screening will occur annually for persons with a previously measured systolic blood pressure of at least $120 \mathrm{~mm} \mathrm{Hg}$ and biannually for everyone else.

\section{Model Design}

ModelHealth: CVD is an annual-cycle microsimulation model designed to estimate the lifetime incidence of CVD events and associated costs in a birth cohort of individuals representative of the US population. The model was designed to ensure consistency for compar- 
Table 2. Baseline ModelHealth: CVD Risk and Event Prevalence

\begin{tabular}{|c|c|c|c|c|c|c|}
\hline Variable & Total, \% & Men, \% & Women, \% & $\begin{array}{c}\text { Non-Hispanic } \\
\text { White, \% }\end{array}$ & $\begin{array}{c}\text { Non-Hispanic } \\
\text { Black, \% }\end{array}$ & Hispanic \% \\
\hline \multicolumn{7}{|l|}{ Hypertension } \\
\hline ModelHealth: CVD & 29.2 & 30.0 & 28.4 & 26.1 & 45.0 & 27.5 \\
\hline NHANES $(2007-2010)^{72}$ & 29.6 & 30.5 & 28.6 & 28.6 & 41.3 & 27.7 \\
\hline \multicolumn{7}{|c|}{ Elevated lipid levels (LDL $\geq 130$ ) } \\
\hline ModelHealth: CVD & 29.8 & 27.8 & 31.6 & 29.6 & 29.9 & 30.2 \\
\hline NHANES $(2009-2012)^{5}$ & 31.7 & 31.0 & 32.0 & 30.7 & 32.2 & 35.3 \\
\hline \multicolumn{7}{|l|}{ Coronary heart disease } \\
\hline ModelHealth: CVD & 6.5 & 8.6 & 4.7 & 6.3 & 7.2 & 6.7 \\
\hline BRFSS $(2010)^{73}$ & 6.0 & 7.8 & 4.6 & 5.8 & 6.5 & 6.1 \\
\hline \multicolumn{7}{|l|}{ Stroke } \\
\hline ModelHealth: CVD & 2.5 & 2.6 & 2.4 & 2.3 & 4.1 & 2.3 \\
\hline BRFSS $(2010)^{74}$ & 2.6 & 2.7 & 2.6 & 2.4 & 3.9 & 2.5 \\
\hline
\end{tabular}

ing outcomes across a wide range of clinical preventive services recommended by the USPSTF and the Advisory Committee on Immunization Practices. ${ }^{24,58}$ Disease outcomes include incidence of myocardial infarction, stroke, congestive heart failure, angina pectoris, intermittent claudication, diabetes, and CVD-related death, as well as for assessment of aspirin, incidence of colorectal cancer. Cardiovascular disease events are predicted by 1 -year risk equations estimated specifically for the model from Framingham Heart Study data. ${ }^{63,64}$ Event risk is based on a person's age, sex, body mass index, systolic blood pressure, high- and low-density lipoprotein cholesterol, smoking status, and history of CVD. Baseline colorectal cancer incidence is derived from US cancer surveillance data. ${ }^{65,66}$ Disease costs are estimated from the Medical Expenditure Panel Survey ${ }^{57}$ and published literature, ${ }^{67}$ with first-year and ongoing disease costs accounted for separately.

The annual progression of body mass index is derived from recall data reported in the Behavioral Risk Factor Surveillance System, ${ }^{68}$ and the natural history of systolic blood pressure and cholesterol is estimated using Framingham Heart Study data. ${ }^{63,64}$ Tobacco initiation and cessation probabilities are derived from the National Health Interview Survey data $^{69}$ and published estimates from longitudinal studies. ${ }^{70,71}$ Screening and treatment for hypertension and dyslipidemia in the model are consistent with national clinical guidelines, ${ }^{60,62}$ and identification and treatment adherence patterns are consistent with the rates observed within NHANES. ${ }^{52-56}$ Use of antihypertensive drugs and lipid-acting agents is modeled as an exogenous treatment effect on systolic blood pressure and cholesterol levels, respectively, and alters disease risk accordingly. Table 2 displays age-adjusted rates of elevated low-density lipoprotein cholesterol level, hypertension, coronary heart disease, and stroke for the baseline model population, stratified by sex and race/ethnicity, and compares them with their respective nationwide indicators.

\section{Analysis Design}

Analyses were conducted from the societal perspective, which includes patient time costs, and in accordance with the reference case of the Panel on Costeffectiveness in Health and Medicine. ${ }^{75}$ All analyses compare outcomes for a simulated population-a 100,000-person birth cohort with demographic and underlying health characteristics representative of the US population of persons aged 18 years-with access to a specified clinical preventive service to the same population, all else held equal, without access to this service. The acceptance rate of the clinical preventive service is assumed to be $90 \%$.

Aspirin use affects the relative risk of myocardial infarction, ischemic stroke, hemorrhagic stroke, incidence of colorectal cancer, major gastrointestinal bleeding, and, in sensitivity analysis, CVD-related mortality. Screening and treatment for lipid disorders affects lowand high-density lipoprotein cholesterol levels. Screening and treatment for hypertension affects systolic blood pressure. Key model parameters are summarized in Table 1, and the effectiveness of treatment is based on calibration to population risk profiles and event rates (Table 2) to account for typical adherence patterns.

Primary outcomes are health impact and costeffectiveness. Health impact is defined as the lifetime net difference, with and without the preventive 
service, in quality-adjusted life years (QALYs) for a 100,000-person birth cohort. When a preventive service increases overall costs, cost-effectiveness is measured in costs per QALY gained and is calculated by the lifetime net difference in discounted costs divided by the lifetime net difference in discounted

\section{Table 3. Predicted Lifetime Health and Cost Outcomes of CVD Clinical Preventive Services in US Population Groups}

\begin{tabular}{|c|c|c|c|c|c|c|c|}
\hline \multirow[b]{2}{*}{ Preventive Service } & \multirow[b]{2}{*}{ US Adults } & \multicolumn{3}{|c|}{ Men } & \multicolumn{3}{|c|}{ Women } \\
\hline & & $\begin{array}{l}\text { Non- } \\
\text { Hispanic } \\
\text { White }\end{array}$ & $\begin{array}{l}\text { Non- } \\
\text { Hispanic } \\
\text { Black }\end{array}$ & Hispanic & $\begin{array}{l}\text { Non- } \\
\text { Hispanic } \\
\text { White }\end{array}$ & $\begin{array}{l}\text { Non- } \\
\text { Hispanic } \\
\text { Black }\end{array}$ & Hispanic \\
\hline \multicolumn{8}{|l|}{$\begin{array}{l}\text { Aspirin for primary } \\
\text { prevention }\end{array}$} \\
\hline Health impact, QALY & 2,200 & 2,700 & 6,800 & 2,300 & 300 & 5,000 & 100 \\
\hline Cost-effectiveness, $\$$ & 31 saved pp & 50 saved $p p$ & 166 saved pp & 47 saved pp & 16,700/QALY & 14 saved pp & 60,200/QALY \\
\hline CVD events, No. & -530 & -750 & $-2,030$ & -840 & -20 & -530 & -20 \\
\hline Ml events & -300 & -470 & -930 & -530 & -20 & -190 & -10 \\
\hline Stroke events & -100 & -110 & -420 & -110 & Longevity ${ }^{a}$ & -240 & -10 \\
\hline CVD deaths & -80 & -110 & -340 & -150 & -10 & -100 & -10 \\
\hline CRC cases, No. & -280 & -370 & -860 & -390 & -80 & -370 & -20 \\
\hline $\begin{array}{l}\text { Persons treated for primary } \\
\text { prevention, No. }\end{array}$ & 15,600 & 22,000 & 39,200 & 27,500 & 2,300 & 21,000 & 2,200 \\
\hline Total costs, $\$$ million & -3.1 & -5.0 & -16.6 & -4.7 & 0.8 & -1.4 & 1.1 \\
\hline Disease costs & -5.5 & -7.9 & -21.7 & -8.3 & -0.3 & -4.8 & -0.2 \\
\hline Screening costs & 1.1 & 1.1 & 1.1 & 1.3 & 0.8 & 1.1 & 1.1 \\
\hline Treatment costs & 1.4 & 1.8 & 4.0 & 2.3 & 0.2 & 2.3 & 0.2 \\
\hline \multicolumn{8}{|l|}{ Cholesterol screening } \\
\hline Health impact, QALY & 14,300 & 17,500 & 25,600 & 19,700 & 7,900 & 14,200 & 9,100 \\
\hline Cost-effectiveness, \$/QALY & 33,800 & 29,400 & 22,900 & 25,600 & 56,500 & 42,100 & 48,900 \\
\hline CVD events, No. & $-3,960$ & $-5,090$ & $-6,630$ & $-5,320$ & $-2,150$ & $-3,520$ & $-2,940$ \\
\hline Ml events & $-1,500$ & $-2,150$ & $-2,860$ & $-2,070$ & -700 & -960 & -930 \\
\hline Stroke events & -40 & -150 & Longevity ${ }^{a}$ & -40 & Longevity ${ }^{a}$ & -130 & -20 \\
\hline CVD deaths & $-1,010$ & $-1,120$ & $-1,450$ & $-1,220$ & -820 & $-1,120$ & -630 \\
\hline $\begin{array}{l}\text { Persons treated for primary } \\
\text { prevention, No. }\end{array}$ & 40,100 & 43,300 & 51,400 & 45,500 & 32,500 & 43,100 & 36,000 \\
\hline Total costs, \$ million & 80.1 & 89.0 & 106.4 & 90.1 & 61.3 & 90.9 & 65.1 \\
\hline Disease costs & -36.3 & -51.5 & -76.4 & -58.8 & -12.1 & -22.6 & -21.9 \\
\hline Screening costs & 16.1 & 17.7 & 18.6 & 18.5 & 13.1 & 18.2 & 14.4 \\
\hline $\begin{array}{l}\text { Treatment and manage- } \\
\text { ment costs }\end{array}$ & 100.3 & 122.8 & 164.3 & 130.3 & 60.2 & 95.4 & 72.5 \\
\hline \multicolumn{8}{|l|}{ Hypertension screening } \\
\hline Health impact, QALY & 15,600 & 11,800 & 17,000 & 14,900 & 16,500 & 24,700 & 16,300 \\
\hline Cost-effectiveness, \$/QALY & 48,500 & 52,200 & 60,600 & 40,800 & 48,300 & 42,100 & 49,500 \\
\hline CVD events, No. & $-4,000$ & $-3,460$ & $-3,740$ & $-4,060$ & $-3,920$ & $-5,930$ & $-4,610$ \\
\hline Ml events & -750 & -880 & -970 & -860 & -600 & -630 & -690 \\
\hline Stroke events & $-1,020$ & -680 & -860 & -720 & $-1,100$ & $-2,250$ & $-1,180$ \\
\hline CVD deaths & $-1,010$ & -780 & $-1,080$ & $-1,040$ & $-1,070$ & $-1,480$ & $-1,080$ \\
\hline $\begin{array}{l}\text { Persons treated for primary } \\
\text { prevention, No. }\end{array}$ & 53,400 & 46,200 & 58,900 & 47,900 & 56,700 & 64,700 & 59,000 \\
\hline Total costs, \$ million & 122.9 & 105.7 & 184.6 & 102.7 & 119.7 & 176.4 & 121.6 \\
\hline Disease costs & -34.8 & -33.6 & -37.5 & -31.6 & -30.7 & -58.2 & -38.0 \\
\hline Screening costs & 33.8 & 34.2 & 27.4 & 34.4 & 35.4 & 28.8 & 34.9 \\
\hline $\begin{array}{l}\text { Treatment and manage- } \\
\text { ment costs }\end{array}$ & 124.0 & 105.1 & 194.7 & 99.9 & 115.0 & 205.9 & 124.8 \\
\hline
\end{tabular}

$\mathrm{CRC}=$ colorectal cancer; $\mathrm{CVD}=$ cardiovascular disease; $\mathrm{MI}=$ myocardial infarction; $\mathrm{pp}=$ per person; QALY = quality-adjusted life year.

Note: All outcomes are standardized for comparison purposes to reflect the lifetime of a 100,000 person US-representative birth cohort within each respective group starting at age 18 years. Cost-effectiveness is expressed in terms of incremental costs per QALY, unless a preventive service is cost-saving overall, in which case, it is expressed in terms of costs saved per person. All costs are expressed in 2012 US dollars.

a Population rates in the outcome are projected to stay the same or increase slightly due to increases in life expectancy attributable to the clinical preventive service. 
QALYs. When a preventive service is cost saving (ie, the lifetime net difference in costs is negative), costeffectiveness is measured in costs saved per person. All costs are denominated in 2012 US dollars, and the discount rate for calculating cost-effectiveness is $3 \%$. Deterministic (one-way) sensitivity analyses of key parameters (Table 1) were conducted by replicating simulations with all other parameters, probabilities, and population characteristics held equal.

This study was granted an exemption by the HealthPartners Institutional Review Board.

\section{RESULTS}

Results from our base case analysis are summarized in Table 3. We estimate that aspirin counseling will save 2,200 QALYs, cholesterol screening and treatment will save 14,300 QALYs, and hypertension screening and treatment will save 15,600 QALYs over the lifetime of a 100,000 person birth cohort in the United States. The health impact of the aspirin, cholesterol, and hypertension services when scaled to a typical US birth cohort size of 4,000,000 persons-also referred to as the "clinically preventable burden" ${ }^{16-}$ - would be approximately 88,000, 572,000, and 624,000 QALYs, respectively. We find that aspirin counseling is cost saving ( $\$ 31$ per person), cholesterol screening costs $\$ 33,800$ per QALY saved, and hypertension screening costs $\$ 48,500$ per QALY saved.

The aspirin counseling service reaches the fewest people $(15,600$ thousand persons in a 100,000 person birth cohort, compared with 40,100 and 53,400 for cholesterol and hypertension screening, respectively) and thereby has a lower overall impact on preventing disease. Cholesterol and hypertension screening are very similar in prevention of overall CVD events (about 4,000 each) and mortality (about 1,000 each), but we find that hypertension screening prevents far more lifetime stroke events ( 1,020 vs 40 ) for this population, contributing to the difference in health impact.

Costs of screening and treatment for the aspirin service are relatively small in comparison to averted disease, resulting in a net cost savings of $\$ 3.1$ million over the lifetime of the birth cohort. For the cholesterol and hypertension services, cost savings from averted disease are substantial_at about $\$ 35$ million each-and exceed the costs of screening, but we estimate the ongoing costs of treating and managing the conditions surpass $\$ 100$ million in each case.

Table 3 also shows that population subgroup outcomes can in many cases diverge in meaningful ways from the population average. For example, aspirin counseling is not expected to be cost saving for white and Hispanic women, primarily because of the small share (less than $2.5 \%$ ) of these women expected to meet USPSTF criteria for routine aspirin use. More-

Table 4. Relative Value of Clinical Preventive Services for CVD, by Outcome, for US Population Group

\begin{tabular}{|c|c|c|c|c|}
\hline \multirow[b]{2}{*}{ Outcome } & \multirow[b]{2}{*}{ US Adults } & \multicolumn{3}{|c|}{ Men } \\
\hline & & Non-Hispanic White & Non-Hispanic Black & Hispanic \\
\hline \multirow{3}{*}{$\begin{array}{l}\text { Largest health impact } \\
\text { (QALY) }\end{array}$} & Hypertension ${ }^{\mathrm{a}}(15,600)$ & Cholesterol $(17,500)$ & Cholesterol $(25,600)$ & Cholesterol $(19,700)$ \\
\hline & Cholesterolb $^{b}(14,300)$ & Hypertension $(11,800)$ & Hypertension $(17,000)$ & Hypertension $(14,900)$ \\
\hline & Aspirinc $(2,200)$ & Aspirin $(2,700)$ & Aspirin $(6,800)$ & Aspirin $(2,300)$ \\
\hline \multirow{3}{*}{$\begin{array}{l}\text { Highest cost-effectiveness } \\
\text { (\$ saved pp, or } \$ \text { per } \\
\text { QALY) }\end{array}$} & Aspirin (31 pp) & Aspirin (50 pp) & Aspirin (166 pp) & Aspirin (47 pp) \\
\hline & Cholesterol $(33,800 / Q A L Y)$ & Cholesterol $(29,400 / Q A L Y)$ & Cholesterol $(22,900 / Q A L Y)$ & Cholesterol $(25,600 / Q A L Y)$ \\
\hline & $\begin{array}{l}\text { Hypertension } \\
\quad(48,500 / Q A L Y)\end{array}$ & $\begin{array}{l}\text { Hypertension } \\
\quad(52,200 / Q A L Y)\end{array}$ & $\begin{array}{l}\text { Hypertension } \\
\quad(60,600 / Q A L Y)\end{array}$ & $\begin{array}{l}\text { Hypertension } \\
\quad(40,800 / Q A L Y)\end{array}$ \\
\hline \multirow{3}{*}{$\begin{array}{l}\text { Most prevented myocar- } \\
\text { dial infarctions (No.) }\end{array}$} & Cholesterol $(1,500)$ & Cholesterol $(2,150)$ & Cholesterol $(2,860)$ & Cholesterol $(2,070)$ \\
\hline & Hypertension (750) & Hypertension (880) & Hypertension (970) & Hypertension (860) \\
\hline & Aspirin (300) & Aspirin (470) & Aspirin (930) & Aspirin (530) \\
\hline \multirow{3}{*}{$\begin{array}{l}\text { Most prevented strokes } \\
\text { (No.) }\end{array}$} & Hypertension $(1,020)$ & Hypertension (680) & Hypertension (860) & Hypertension (720) \\
\hline & Aspirin (100) & Cholesterol (150) & Aspirin (420) & Aspirin (110) \\
\hline & Cholesterol (40) & Aspirin (110) & Cholesterol (longevity ${ }^{\mathrm{d}}$ ) & Cholesterol (40) \\
\hline
\end{tabular}

CVD = cardiovascular disease; $\mathrm{pp}=$ per person; QALY = quality-adjusted life year.

Note: Preventive services are aspirin counseling, hypertension screening, and cholesterol screening. All outcomes are for the lifetime of a 100,000-person US-representative birth cohort within each respective group starting at age 18 years. Cost-effectiveness is expressed in terms of incremental costs per QALY, unless a preventive service is cost saving overall, in which case, it is expressed in terms of costs saved per person. All costs expressed in 2012 us dollars.

a Hypertension screening and management in adults.

${ }^{\mathrm{b}}$ Lipid disorder screening and management in adults.

' Aspirin for the primary prevention of cardiovascular disease and colorectal cancer.

${ }^{d}$ Population rates in the outcome are projected to stay the same or increase slightly because of increases in life expectancy attributable to the clinical preventive service. 
over, because of differences in CVD risk profiles at ages 50 to 59 years, approximately one-tenth of nonHispanic white and Hispanic women and one-half of non-Hispanic black women meet recommended guidelines for initiating use of aspirin for primary prevention compared with their male counterparts. Differences in risk factor and disease prevalence (Table 2) also help to explain why non-Hispanic black men and women are generally expected to see the largest benefits across all 3 services, why men are shown to benefit more from cholesterol screening (which has a primary benefit in preventing heart disease), and why women overall are expected to benefit slightly more from hypertension screening (which also has substantial benefits in preventing stroke, for which longer life expectancy contributes to higher lifetime incidence in women ${ }^{77,78}$ ).

These trends are made even clearer in Table 4, which translates the results in Table 3 into a relative value ordering for the overall population and for each sex and race/ethnicity subgroup based on health impact or cost-effectiveness. In addition, Table 4 includes two clinical outcome objectives most likely to resonate with patient preferences, the most prevented myocardial infarctions or strokes. ${ }^{79}$ Top services for these outcomes are clear: cholesterol screening has the most potential to prevent myocardial infarctions and hypertension screening has the most potential to prevent strokes-for all groups.

\section{Results of Sensitivity Analysis}

Findings can vary substantially with alternative assumptions on key model parameters (Table 5). Results for the aspirin service are most sensitive overall, because of the uncertainty in the scale (eg, how much long-term use increases the relative risk for hemorrhagic stroke) and scope (eg, whether aspirin for primary prevention can reduce CVD mortality) of aspirin's effects. Health impact estimates for aspirin counseling range from approximately 200 to 4,000 QALYs, and cost-effectiveness in the worst case is about $\$ 92,000 /$ QALY saved. Also noteworthy is the sensitivity in cost-effectiveness for cholesterol and hypertension screening associated with the cost of medications. If all patients were able to take advantage of the lowest cost cholesterol and blood pressure drugs, cost-effectiveness could improve to nearly $\$ 5,000$ /QALY for cholesterol screening and $\$ 26,000$ / QALY for hypertension screening.

\section{DISCUSSION}

The case for prevention can sometimes be a challenging one; benefits often accrue far in the future, and costs tend to be highest upfront. Nevertheless, our analysis indicates that clinical services for the primary prevention of CVD can avert substantial disease burden and potentially save costs. In our accompanying comparison across all clinical preventive services, estimates of health impact for a 100,000-person birth cohort range from 100 to 83,200 (median $=2,900)$ QALYs, and estimates of cost-effectiveness range from cost saving to $\$ 782,600$ $($ median $=\$ 36,800)$ per QALY saved ${ }^{24}$ In this study, we find that initiation of aspirin use among adults at elevated CVD risk and aged 50 to 59 years has a moderate health impact $(2,200$ QALYs $)$ but is also among the few services expected to save costs overall. Screenings for lipid disorders and hypertension are among the top services for health impact (at 14,300 and 15,600 QALYs, respectively) and rank in the middle of the pack for cost-effectiveness (at $\$ 33,800$ and $\$ 48,500$ per QALY, respectively_both of which also compare favorably with the most commonly cited cost-effectiveness 
Table 5. Sensitivity to Key Parameter Changes

\begin{tabular}{|c|c|c|c|c|}
\hline Parameter & $\begin{array}{c}\text { Health Impact } \\
\text { QALY }\end{array}$ & $\begin{array}{c}\text { Cost-Effectiveness } \\
\$\end{array}$ & $\begin{array}{c}\text { Cardiovascular } \\
\text { Disease Event, No. }\end{array}$ & $\begin{array}{l}\text { Total Cost } \\
\text { \$ Million }\end{array}$ \\
\hline \multicolumn{5}{|l|}{ Aspirin for primary prevention } \\
\hline Base case & 2,200 & 31 saved $p p$ & -530 & -3.1 \\
\hline \multicolumn{5}{|l|}{ Treatment efficacy } \\
\hline Low & 200 & 91,700/QALY & -50 & 2.5 \\
\hline High & 4,000 & 68 saved $p p$ & -910 & -6.8 \\
\hline \multicolumn{5}{|l|}{ Treatment effectiveness } \\
\hline$-10 \%$ (60\% effectiveness) & 1,800 & 18 saved $p p$ & -370 & -1.8 \\
\hline$+10 \%$ (80\% effectiveness) & 2,600 & 45 saved $p p$ & -720 & -4.5 \\
\hline \multicolumn{5}{|l|}{ Disease costs } \\
\hline$-25 \%$ & 2,200 & 17 saved $\mathrm{pp}$ & -530 & -1.7 \\
\hline$+25 \%$ & 2,200 & 45 saved $\mathrm{pp}$ & -530 & -4.5 \\
\hline \multicolumn{5}{|l|}{ Screening and medication costs } \\
\hline Screening (clinic) costs, $-25 \%$ & 2,200 & 32 saved pp & -530 & -3.2 \\
\hline Screening (clinic) costs, $+25 \%$ & 2,200 & 30 saved $p p$ & -530 & -3.0 \\
\hline Bulk aspirin $(-35 \%), \$ 11.93 / y$ & 2,200 & 36 saved $p p$ & -530 & -3.6 \\
\hline Name brand aspirin (+32\%), $\$ 24.04 / y$ & 2,200 & 27 saved pp & -530 & -2.7 \\
\hline No patient time cost & 2,200 & 37 saved pp & -530 & -3.7 \\
\hline \multicolumn{5}{|l|}{ QALY decrements } \\
\hline-0.10 QALY & 2,100 & 31 saved $p p$ & -530 & -3.1 \\
\hline+0.10 QALY & 2,300 & 31 saved pp & -530 & -3.1 \\
\hline \multicolumn{5}{|l|}{ Cholesterol screening } \\
\hline Base case & 14,300 & 33,800/QALY & $-3,960$ & 80.1 \\
\hline \multicolumn{5}{|l|}{ Treatment effectiveness } \\
\hline$-10 \%$ (60\% effectiveness) & 12,400 & $35,100 / Q A L Y$ & $-3,510$ & 71.8 \\
\hline$+10 \%$ ( $80 \%$ effectiveness) & 18,300 & $27,200 / Q A L Y$ & $-5,140$ & 81.9 \\
\hline \multicolumn{5}{|l|}{ Disease costs } \\
\hline$-25 \%$ & 14,300 & $37,600 /$ QALY & $-3,960$ & 89.2 \\
\hline$+25 \%$ & 14,300 & 30,000/QALY & $-3,960$ & 71.0 \\
\hline \multicolumn{5}{|l|}{ Screening, management, and medication costs } \\
\hline Screening and management (clinic) costs, $-25 \%$ & 14,300 & 30,800/QALY & $-3,960$ & 73.0 \\
\hline Screening and management (clinic) costs, $+25 \%$ & 14,300 & $36,800 / Q A L Y$ & $-3,960$ & 87.2 \\
\hline Discount generic medications (-91\%), $\$ 36.70 / y$ & 14,300 & $5,300 / Q A L Y$ & $-3,960$ & 12.6 \\
\hline Name brand medications (+804\%), $\$ 3,818.73 / y$ & 14,300 & $284,800 / Q A L Y$ & $-3,960$ & 675.1 \\
\hline No patient time cost & 14,300 & 28,000/QALY & $-3,960$ & 66.4 \\
\hline \multicolumn{5}{|l|}{ QALY decrements } \\
\hline-0.10 QALY & 13,400 & $37,400 / Q A L Y$ & $-3,960$ & 80.1 \\
\hline+0.10 QALY & 15,000 & $31,400 /$ QALY & $-3,960$ & 80.1 \\
\hline \multicolumn{5}{|l|}{ Hypertension screening } \\
\hline Base case & 15,600 & $48,500 / Q A L Y$ & $-4,000$ & 122.9 \\
\hline \multicolumn{5}{|l|}{ Treatment effectiveness } \\
\hline$-10 \%$ (60\% effectiveness) & 11,800 & 60,300/QALY & $-3,060$ & 115.7 \\
\hline$+10 \%$ ( $80 \%$ effectiveness) & 19,800 & $39,700 / Q A L Y$ & $-5,100$ & 127.1 \\
\hline \multicolumn{5}{|l|}{ Disease costs } \\
\hline$-25 \%$ & 15,600 & $52,000 / \mathrm{QALY}$ & $-4,000$ & 131.6 \\
\hline$+25 \%$ & 15,600 & $45,100 /$ QALY & $-4,000$ & 114.2 \\
\hline \multicolumn{5}{|l|}{ Screening, management, and medication costs } \\
\hline Screening and management (clinic) costs, $-25 \%$ & 15,600 & $44,400 / \mathrm{QALY}$ & $-4,000$ & 112.5 \\
\hline Screening and management (clinic) costs, $+25 \%$ & 15,600 & $52,500 / Q A L Y$ & $-4,000$ & 133.1 \\
\hline Discount generic medications (-82\%), $\$ 36.70 / y$ & 15,600 & $26,200 / Q A L Y$ & $-4,000$ & 66.5 \\
\hline Name brand medications $(+1,973 \%), \$ 4,216.16 / y$ & 15,600 & $584,600 / Q A L Y$ & $-4,000$ & $1,481.0$ \\
\hline No patient time cost & 15,600 & $34,200 / \mathrm{QALY}$ & $-4,000$ & 86.6 \\
\hline \multicolumn{5}{|l|}{ QALY decrements } \\
\hline$-0.10 \mathrm{QALY}$ & 14,900 & $52,300 / Q A L Y$ & $-4,000$ & 122.9 \\
\hline$+0.10 \mathrm{QALY}$ & 15,700 & 46,800/QALY & $-4,000$ & 122.9 \\
\hline
\end{tabular}


thresholds of $\$ 50,000$ and $\$ 100,000$ per QALY $^{80}$ ). As a result, all 3 CVD services rank highly among other clinical preventive services, scoring at least 7 of 10 possible points on combined health impact and cost-effectiveness. ${ }^{24}$

This comparative analysis is the first of its kind to use an integrated, validated microsimulation model to estimate the lifetime impacts from USPSTF-recommended CVD prevention activities for a US-representative birth cohort, and this novel approach lends multiple strengths. The first strength is that microsimulation allows for the assessment of clinical services targeted to persons with specific characteristics, such as by age, sex, and underlying cardiovascular risk factors. Age, sex, and race/ethnicity are correlated with CVD risk profiles that may indicate both eligibility for a preventive service and the likelihood of benefit from prevention activities. This relationship is most notably important for aspirin, where relatively few women aged 50 to 59 years (a ratio of 1:5 compared with men) meet the 10\% 10-year CVD risk threshold identified by the USPSTF, and across all services for the non-Hispanic black population, which tends to have greater CVD risk at younger ages compared with other population groups.

As such, an important second benefit of our analysis is the stratification of results by population subgroups, and our analysis shows that a population-wide assessment of prevention activities can mask notable differences in the health impact and cost-effectiveness by sex and race/ethnicity. For example, contrary to our findings for the overall population (and for men), women are generally expected to benefit more from screening for hypertension than for dyslipidemia. Also notable is that cost savings of aspirin are not found for white and Hispanic women and that non-Hispanic black Americans have the greatest overall opportunities for reducing disease burden. These stratified results support tailoring prevention priorities to individual patient preferences and needs and highlight opportunities to reduce health disparities.

A third notable strength of our approach is that the microsimulation model used in our analysis accounts for the dynamics of competing risks among nonfatal and fatal CVD and other causes of death in quantifying net benefits. The model also accounts for background use of other primary prevention activities and secondary prevention subsequent to a CVD event. When the first nonfatal CVD event of a simulated person is prevented or delayed as a result of a clinical preventive service, their use of aspirin, statins, and/ or antihypertensive medications for primary or secondary prevention also may be prevented or delayed. The prevention or delay of an initial nonfatal event also changes the risk of subsequent nonfatal and fatal events. This approach provides a more realistic estimate of the marginal value of a clinical service for primary prevention relative to secondary prevention.

Our findings do not depart dramatically or unexpectedly from previous National Commission on Prevention Priorities rankings. Previously, cholesterol and hypertension screening scored highly for health impact and scored in the middle to lower half of services for cost-effectiveness, as they still do. ${ }^{15,81}$ Aspirin counseling was similarly found to be cost-saving, but it also previously scored very highly for health impact. ${ }^{15}$ The lower potential net health benefit from aspirin counseling in our analysis is largely a result of the substantially narrowed target population for the service in the current recommendation and the changes to the underlying evidence of aspirin's benefits and harms, including lower expected effectiveness in preventing nonfatal myocardial infarction and stroke-which no longer differ by sex-and accounting for fatalities from aspirin-induced bleeding. ${ }^{27,32,82,83}$

This study contributes to a broader evidence base that uses modeling to assess the incremental and comparative effectiveness of clinical services for the primary prevention of CVD. Direct comparisons are often difficult because of differing research questions and methods. For example, an analysis by Kahn and colleagues $^{84}$ using the Archimedes model shares many similarities with ours-both use a single integrated microsimulation to evaluate individual CVD prevention activities targeted to and treating person-level characteristics for the US population with concurrent use of other prevention activities at contemporary levels_-but results are difficult to compare because their evaluation was based on a cross-section of the US population over 30 years, estimated the marginal benefit of ideal prevention to current care, and did not include population screening costs. Similarly, other studies differ from ours in some of the following ways: they evaluate an increase in utilization or adherence to clinical preventive services from contemporary levels, ${ }^{85-94}$ the modeling unit is higher than person level (eg, population cohort or system dynamics modeling), ${ }_{1}^{85-88,90-107}$ the modeled population is cross-sectional rather than a birth cohort, ${ }^{*}$ the modeled population is not US based $_{1}^{\dagger}$ the time horizon is less than lifetime, ${ }^{\ddagger}$ results are not stratified by sex or race/ethnicity, ${ }^{\S}$ and/or the evaluation focuses on the value of a single or combined composite CVD preventive service. ${ }^{* *}$ Nevertheless,

\footnotetext{
* References 85-91, 93, 94, 101, 104, 106, 108.

† References 91-94, 98, 101-106, 108, 109.

† References 85-90, 92-94,101, 104, 108.

$\S$ References 85-90, 95, 100, 101, 104, 106, 108

** References 87-89, 91, 92, 95-103, 105-109.
} 
common threads across these evaluations include the sizable disease prevention potential for screening for and treating lipid disorders and hypertension and good cost-effectiveness for aspirin chemoprophylaxis.

The microsimulation model design and the results of these analyses are limited by the quality of data and evidence used to inform them. Our sensitivity analysis results indicate that health impact estimates are especially sensitive to the fidelity and adherence to treatment plans for all services. Uncertainty in the efficacy of aspirin with respect to benefits and harms also limits the precision of our results. For patients treating lipid disorders or hypertension, the cost-effectiveness proposition is highly dependent on the cost of medications. The marginal benefit of a clinical preventive service is also dependent on baseline risk factors and disease rates, but ModelHealth: CVD is shown to validate well with US data (Table 2).

Clinical prevention and practice recommendations, treatments, and effectiveness evidence are continually in flux. Since the conduct of these analyses, the USPSTF updated its recommendation for blood pressure screening. ${ }^{110}$ In its update, the Task Force recommends the use of ambulatory or home blood pressure monitoring before initiating treatment-a change that some evidence suggests could lower the overall cost of the service based on improved hypertension diagnosis. ${ }^{11,112}$ Practice guidelines for managing high cholesterol levels and hypertension have also recently been revised, ${ }_{1}^{113,114}$ although evidence is not yet clear how and whether clinical practice patterns have shifted as a result. Proprotein convertase subtilisin-kexin type 9 (PCSK9) inhibitors are emerging as a new drug class for the treatment of lipid disorders, ${ }_{1}^{115,116}$ and several ongoing aspirin trials may reveal new benefits or harms. ${ }^{30,32,117-120}$ The evolving environment will continue to affect the impact and value of clinical preventive services for CVD.

Policy makers are often interested in prioritizing efforts and investments to increase prevention utilization from contemporary rates. In cases where use is relatively high, such as with screening for hypertension and lipid disorders, ${ }^{121}$ incremental gains may be modest. Still, almost one-half of those with a diagnosis of hypertension do not meet recommended blood pressure goals, ${ }^{122}$ and our sensitivity analysis, along with the findings of others, ${ }^{84}$ indicates that major reductions in disease and cost burdens can be realized with improvements in treatment effectiveness. Our findings also highlight opportunities for closing gaps among populations for which persistent care access and quality disparities have hindered uptake of effective preventive services ${ }^{123-127}$ and advance the case toward a personalized approach to quantitative prior- ity setting. ${ }^{128}$ Overall, our findings affirm that aspirin counseling for primary prevention and asymptomatic screening and treatment of hypertension and lipid disorders should remain among the top prevention priorities for adults in primary care.

To read or post commentaries in response to this article, see it online at http://www.annfammed.org/content/15/1/23.

Key words: Cardiovascular diseases; cost-effectiveness; aspirin; cholesterol; lipid disorders; hypertension; blood pressure, high; mass screening; primary prevention

Submitted April 20, 2016; submitted, revised, October 14, 2016; accepted October 29, 2016.

Funding support: This study was supported by the Centers for Disease Control and Prevention (Cooperative Agreement Numbers 5H25PS003610 and U58/CC0322077-02-01), American Heart Association, Robert Wood Johnson Foundation, WellPoint (now Anthem) Foundation, and the HealthPartners Institute for Education and Research.

Disclaimer: The contents are solely the responsibility of the authors and do not necessarily represent the official views of the Centers for Disease Control and Prevention.

Acknowledgments: We are grateful for the guidance of the National Commission on Prevention Priorities: Eduardo Sanchez, MD, MPH (Chair); Kim Barnhill, MS, MPH; Ross C. Brownson, PhD; Michael C. Caldwell, MD, MPH; Jonathan E. Fielding, MD, MPH, MBA; David W. Fleming, MD; Anne C. Haddix, PhD; George Isham MD; Lovell Jones, PhD; Warren A. Jones, MD, FAAFP; Linda Kinsinger, MD, MPH; Samuel Nussbaum, MD; C. Tracy Orleans, PhD; Marcel Salive, MD, MPH; Steven L. Solomon, MD; Kurt C. Stange, MD, PhD; Steven M. Teutsch, MD, MPH; Cristie Upshaw Travis, MS; Stephen Williams, MEd, MPA; and Steven $\mathrm{H}$. Woolf, MD, MPH.

Supplemental materials: Available at http://www.annfammed. org/content/15/1/23/suppl/DC1/.

\section{References}

1. Centers for Disease Control and Prevention (CDC). Decline in deaths from heart disease and stroke-United States, 1900-1999. MMWR Morb Mortal Wkly Rep. 1999;48(30):649-656.

2. Ford ES, Ajani UA, Croft JB, et al. Explaining the decrease in U.S. deaths from coronary disease, 1980-2000. N Engl J Med. 2007; 356(23):2388-2398.

3. Heron M. Deaths: leading causes for 2011. Natl Vital Stat Rep. 2015;64(7):1-96.

4. Johnson NB, Hayes LD, Brown K, Hoo EC, Ethier KA; Centers for Disease Control and Prevention (CDC). CDC National Health Report: leading causes of morbidity and mortality and associated behavioral risk and protective factors-United States, 2005-2013. MMWR Suppl. 2014;63(4):3-27.

5. Mozaffarian D, Benjamin EJ, Go AS, et al; American Heart Association Statistics Committee and Stroke Statistics Subcommittee. Heart disease and stroke statistics-2015 update: a report from the American Heart Association. Circulation. 2015;131(4):e29-e322.

6. Heidenreich PA, Trogdon JG, Khavjou OA, et al; American Heart Association Advocacy Coordinating Committee; Stroke Council; Council on Cardiovascular Radiology and Intervention; Council on Clinical Cardiology; Council on Epidemiology and Prevention; Council on Arteriosclerosis; Thrombosis and Vascular Biology; 
Council on Cardiopulmonary; Critical Care; Perioperative and Resuscitation; Council on Cardiovascular Nursing; Council on the Kidney in Cardiovascular Disease; Council on Cardiovascular Surgery and Anesthesia, and Interdisciplinary Council on Quality of Care and Outcomes Research. Forecasting the future of cardiovascular disease in the United States: a policy statement from the American Heart Association. Circulation. 2011;123(8):933-944.

7. Yang Q, Cogswell ME, Flanders WD, et al. Trends in cardiovascular health metrics and associations with all-cause and CVD mortality among US adults. JAMA. 2012;307(12):1273-1283.

8. Patel SA, Winkel M, Ali MK, Narayan KM, Mehta NK. Cardiovascular mortality associated with 5 leading risk factors: national and state preventable fractions estimated from survey data. Ann Intern Med. 2015;163(4):245-253.

9. Cooper R, Cutler J, Desvigne-Nickens P, et al. Trends and disparities in coronary heart disease, stroke, and other cardiovascular diseases in the United States: findings of the national conference on cardiovascular disease prevention. Circulation. 2000;102(25): 3137-3147.

10. Murray CJ, Kulkarni SC, Michaud C, et al. Eight Americas: investigating mortality disparities across races, counties, and racecounties in the United States. PLoS Med. 2006;3(9):e260.

11. Woolf SH, Stange KC. A sense of priorities for the healthcare commons. Am J Prev Med. 2006;31(1):99-102.

12. Aspirin for the primary prevention of cardiovascular events: recommendation and rationale. Ann Intern Med. 2002 Jan 15 2002; 136(2):157-160.

13. Screening adults for lipid disorders: recommendations and rationale. Am J Prev Med. 2001;20(3 Suppl):73-76.

14. U.S. Preventive Services Task Force. Screening for high blood pressure: recommendations and rationale. Am J Prev Med. 2003;25(2): 159-164.

15. Maciosek MV, Coffield AB, Edwards NM, Flottemesch TJ, Goodman MJ, Solberg LI. Priorities among effective clinical preventive services results of a systematic review and analysis. Am J Prev Med. 2006;31(1):52-61.

16. Bibbins-Domingo K; U.S. Preventive Services Task Force. Aspirin Use for the Primary Prevention of Cardiovascular Disease and Colorectal Cancer: U.S. Preventive Services Task Force Recommendation Statement. Ann Intern Med. 2016;164(12):836-845.

17. US Preventive Services Task Force. Screening for lipid disorders in adults: recommendation statement, 2008. https://www. uspreventiveservicestaskforce.org/Page/Document/UpdateSummaryFinal/lipid-disorders-in-adults-cholesterol-dyslipidemia-screening. Published Jun 2008. Updated Jul 2015

18. U.S. Preventive Services Task Force. Screening for high blood pressure: U.S. Preventive Services Task Force reaffirmation recommendation statement. Ann Intern Med. 2007;147(11):783-786.

19. Meyer J, Parker A, Tharaldson A, Peterson C. 2006 Drug Trend Report. Express Scripts. https://www.express-scripts.com/research/ research/dtr/archive/2006/. Published Apr 2007. Accessed Apr 2009.

20. 2014 Drug Trend Report. Express Scripts. https://www.expressscripts.com/research/research/dtr/archive/2006/. Published Mar 2015. Accessed Sep 2015.

21. Frieden TR, Berwick DM. The "Million Hearts" initiative-preventing heart attacks and strokes. N Engl J Med. 2011;365(13):e27.

22. Saydah S, Bullard KM, Cheng Y, et al. Trends in cardiovascular disease risk factors by obesity level in adults in the United States, NHANES 1999-2010. Obesity (Silver Spring). 2014;22(8):1888-1895.

23. Ritchey MD, Wall HK, Gillespie C, George MG, Jamal A; Division for Heart Disease and Stroke Prevention, CDC. Million hearts: prevalence of leading cardiovascular disease risk factors-United States, 2005-2012. MMWR Morb Mortal Wkly Rep. 2014;63(21):462-467.
24. Maciosek MV, LaFrance AB, Dehmer SP, et al. Updated priorities among effective clinical preventive services. Ann Fam Med. 2016; 15(1):14-22.

25. US Preventive Services Task Force. Aspirin for the prevention of cardiovascular disease: U.S. Preventive Services Task Force recommendation statement. Ann Intern Med. 2009;150(6):396-404.

26. U.S. Preventive Services Task Force. Routine aspirin or nonsteroidal anti-inflammatory drugs for the primary prevention of colorectal cancer: U.S. Preventive Services Task Force recommendation statement. Ann Intern Med. 2007;146(5):361-364.

27. Chubak J, Kamineni A, Buist DSM, Anderson ML, Whitlock EP. Aspirin Use for the Prevention of Colorectal Cancer: An Updated Systematic Evidence Review for the U.S. Preventive Services Task Force. Rockville, MD: Agency for HealthcareResearch and Quality; 2015. AHRQ Publication No. 15-05228-EF-1.

28. Chubak J, Whitlock EP, Williams SB, et al. Aspirin for the prevention of cancer incidence and mortality: systematic evidence reviews for the U.S. Preventive Services Task Force. Ann Intern Med. 2016;164(12):814-825.

29. Guirguis-Blake JM, Evans CV, Senger CA, O'Connor EA, Whitlock EP. Aspirin for the primary prevention of cardiovascular events: a systematic evidence review for the U.S. Preventive Services Task Force. Ann Intern Med. 164;(12):804-813.

30. Guirguis-Blake JM, Evans CV, Senger CA, Rowland MG, O'Connor EA, Whitlock EP. Aspirin for the Primary Prevention of Cardiovascular Events: A Systematic Evidence Review for the U.S. Preventive Services Task Force. Rockville, MD: Agency for HealthcareResearch and Quality; 2015. AHRQ Publication No. 13-05195-EF-1.

31. Whitlock EP, Burda BU, Williams SB, Guirguis-Blake JM, Evans CV. Bleeding risks with aspirin use for primary prevention in adults: a systematic review for the U.S. Preventive Services Task Force. Ann Intern Med. 2016;164(12):826-835.

32. Whitlock EP, Williams SB, Burda BU, Feightner A, Beil T. Aspirin Use in Adults: Cancer, All-Cause Mortality, and Harms: A Systematic Evidence Review for the U.S. Preventive Services Task Force. Rockville, MD: Agency for HealthcareResearch and Quality; 2015. AHRQ Publication No. 13-05193-EF-1.

33. Randomised trial of cholesterol lowering in 4444 patients with coronary heart disease: the Scandinavian Simvastatin Survival Study (4S). Lancet. 1994;344(8934):1383-1389.

34. Downs JR, Clearfield M, Weis S, et al. Primary prevention of acute coronary events with lovastatin in men and women with average cholesterol levels: results of AFCAPS/TexCAPS. Air Force/Texas Coronary Atherosclerosis Prevention Study. JAMA. 1998;279(20): 1615-1622.

35. Holdaas $H$, Fellström B, Jardine AG, et al; Assessment of LEscol in Renal Transplantation (ALERT) Study Investigators. Effect of fluvastatin on cardiac outcomes in renal transplant recipients: a multicentre, randomised, placebo-controlled trial. Lancet. 2003;361(9374): 2024-2031.

36. Sever PS, Dahlof B, Poulter NR, et al. Prevention of coronary and stroke events with atorvastatin in hypertensive patients who have average or lower-than-average cholesterol concentrations, in the Anglo-Scandinavian Cardiac Outcomes Trial-Lipid Lowering Arm (ASCOT-LLA): a multicentre randomised controlled trial. Lancet. 2003;361(9364):1149-1158.

37. Knopp RH, d'Emden M, Smilde JG, Pocock SJ. Efficacy and safety of atorvastatin in the prevention of cardiovascular end points in subjects with type 2 diabetes: the Atorvastatin Study for Prevention of Coronary Heart Disease Endpoints in non-insulin-dependent diabetes mellitus (ASPEN). Diabetes Care. 2006;29(7):1478-1485.

38. MRC/BHF Heart Protection Study of antioxidant vitamin supplementation in 20,536 high-risk individuals: a randomised placebocontrolled trial. Lancet. 2002;360(9326):23-33. 
39. Prevention of cardiovascular events and death with pravastatin in patients with coronary heart disease and a broad range of initial cholesterol levels. The Long-Term Intervention with Pravastatin in Ischaemic Disease (LIPID) Study Group. N Engl J Med. 1998;339(19): 1349-1357.

40. Shepherd J, Blauw GJ, Murphy MB, et al. Pravastatin in elderly individuals at risk of vascular disease (PROSPER): a randomised controlled trial. Lancet. 2002;360(9346):1623-1630.

41. Shepherd J, Cobbe SM, Ford I, et al. Prevention of coronary heart disease with pravastatin in men with hypercholesterolemia. West of Scotland Coronary Prevention Study Group. N Engl J Med. 1995: 333(20):1301-1307.

42. Liu L, Zhang Y, Liu G, Li W, Zhang X, Zanchetti A; FEVER Study Group. The Felodipine Event Reduction (FEVER) Study: a randomized long-term placebo-controlled trial in Chinese hypertensive patients. J Hypertens. 2005;23(12):2157-2172.

43. Beckett NS, Peters R, Fletcher AE, et al; HYVET Study Group. Treatment of hypertension in patients 80 years of age or older. $N$ Engl J Med. 2008;358(18):1887-1898.

44. MRC trial of treatment of mild hypertension: principal results. Medical Research Council Working Party. Br Med J (Clin Res Ed). 1985;291(6488):97-104.

45. Medical Research Council trial of treatment of hypertension in older adults: principal results. MRC Working Party. BMJ. 1992; 304(6824):405-412.

46. PROGRESS Collaborative Group. Randomised trial of a perindoprilbased blood-pressure-lowering regimen among 6,105 individuals with previous stroke or transient ischaemic attack. Lancet. 2001; 358(9287):1033-1041.

47. Prevention of stroke by antihypertensive drug treatment in older persons with isolated systolic hypertension. Final results of the Systolic Hypertension in the Elderly Program (SHEP). SHEP Cooperative Research Group. JAMA. 1991;265(24):3255-3264.

48. Dahlof B, Lindholm LH, Hansson L, Schersten B, Ekbom T, Wester PO. Morbidity and mortality in the Swedish Trial in Old Patients with Hypertension (STOP-Hypertension). Lancet. 1991 Nov 23 1991;338(8778):1281-1285.

49. Liu L, Wang JG, Gong L, Liu G, Staessen JA; Systolic Hypertension in China (Syst-China) Collaborative Group. Comparison of active treatment and placebo in older Chinese patients with isolated systolic hypertension. J Hypertens. 1998;16(12 Pt 1):1823-1829.

50. Staessen JA, Fagard R, Thijs L, et al. Randomised double-blind comparison of placebo and active treatment for older patients with isolated systolic hypertension. The Systolic Hypertension in Europe (Syst-Eur) Trial Investigators. Lancet. 1997;350(9080):757-764.

51. National Center for Health Statistics. National Health Interview Survey, 2014. Hyattsville, MD: National Center for Health Statistics, Centers for Disease Control and Prevention; 2015.

52. National Center for Health Statistics. National Health and Nutrition Examination Survey Data, 2001-2002. Hyattsville, MD: Centers for Disease Control and Prevention; 2004. http://wwwn.cdc.gov/nchs/ nhanes/search/nhanes01_02.aspx

53. National Center for Health Statistics. National Health and Nutrition Examination Survey Data, 2003-2004. Hyattsville, MD: Centers for Disease Control and Prevention; 2006. http://wwwn.cdc.gov/nchs/ nhanes/search/nhanes03_04.aspx

54. National Center for Health Statistics. National Health and Nutrition Examination Survey Data, 2005-2006. Hyattsville, MD: Centers for Disease Control and Prevention; 2008. http://wwwn.cdc.gov/nchs/ nhanes/search/nhanes05_06.aspx

55. National Center for Health Statistics. National Health and Nutrition Examination Survey Data, 2007-2008. Hyattsville, MD: Centers for Disease Control and Prevention; 2010. http://wwwn.cdc.gov/nchs/ nhanes/search/nhanes07_08.aspx
56. National Center for Health Statistics. National Health and Nutrition Examination Survey Data, 2009-2010. Hyattsville, MD: Centers for Disease Control and Prevention; 2012. http://wwwn.cdc.gov/nchs/ nhanes/search/nhanes09_10.aspx

57. Agency for Healthcare Research and Quality. Medical Expenditure Panel Survey, 2001-2010. http://meps.ahrq.gov/mepsweb/.

58. Maciosek MV, Edwards NM, Coffield AB, et al. Priorities among effective clinical preventive services methods. Am J Prev Med. 2006:31(1):90-96.

59. Helfand M, Carson S. Screening for Lipid Disorders in Adults: Selective Update of 2001 US Preventive Services Task Force Review. Rockville, MD: Agency for Healthcare Research and Quality;2008.

60. Third Report of the National Cholesterol Education Program (NCEP) Expert Panel on Detection, Evaluation, and Treatment of High Blood Cholesterol in Adults (Adult Treatment Panel III) final report. Circulation. 2002;106(25):3143-3421.

61. Wolff T, Miller T. Evidence for the reaffirmation of the U.S. Preventive Services Task Force recommendation on screening for high blood pressure. Ann Intern Med. 2007;147(11):787-791.

62. Chobanian AV, Bakris GL, Black HR, et al. Seventh report of the Joint National Committee on Prevention, Detection, Evaluation, and Treatment of High Blood Pressure. Hypertension. 2003;42(6):1206-1252.

63. Framingham Heart Study-Cohort. Biologic Specimen and Data Repository Information Coordinating Center, National Institutes of Health. 2010. https://biolincc.nhlbi.nih.gov/studies/ framcohort/?q=Framingham $\% 20$ Heart $\% 20$ Study

64. Framingham Heart Study-Offspring. Biologic Specimen and Data Repository Information Coordinating Center, National Institutes of Health. 2010. https://biolincc.nhlbi.nih.gov/studies/fram offspring $/ ? q=$ Framingham $\% 20$ Heart\%20Study

65. Surveillance Research Program, National Cancer Institute SEER*Stat Software [computer program]. Version 8.1.5. Bethesda, MD: National Cancer Institute; 2014.

66. Smoking-Attributable Mortality, Morbidity, and Economic Costs (SAMMEC): Adult SAMMEC and Maternal and Child Health (MCH) SAMMEC software. 2007. https://chronicdata.cdc.gov/ Health-Consequences-and-Costs/Smoking-Attributable-MortalityMorbidity-and-Econo/3kjq-j5dm/data

67. Mariotto AB, Yabroff KR, Shao Y, Feuer EJ, Brown ML. Projections of the cost of cancer care in the United States: 2010-2020. J Natl Cancer Inst. 2011;103(2):117-128.

68. Department of Health and Human Services, Centers for Disease Control and Prevention. Behavioral Risk Factor Surveillance System Survey Data 2009. Atlanta, Georgia: Centers for Disease Control and Prevention; 2010. http://www.cdc.gov/brfss/annual_data/ annual_2009.htm.

69. National Center for Health Statistics. National Health Interview Survey, 2007. Hyattsville, MD: National Center for Health Statistics, Centers for Disease Control and Prevention; 2008.

70. Hughes JR, Keely JP, Niaura RS, Ossip-Klein DJ, Richmond RL, Swan GE. Measures of abstinence in clinical trials: issues and recommendations. Nicotine Tob Res. 2003;5(1):13-25.

71. Wetter DW, Cofta-Gunn L, Fouladi RT, Cinciripini PM, Sui D, Gritz ER. Late relapse/sustained abstinence among former smokers: a longitudinal study. Prev Med. 2004;39(6):1156-1163.

72. Gillespie CD, Hurvitz KA; Centers for Disease Control and Prevention (CDC). Prevalence of hypertension and controlled hypertensionUnited States, 2007-2010. MMWR Suppl. 2013;62(3):144-148.

73. Centers for Disease Control and Prevention (CDC). Prevalence of coronary heart disease-United States, 2006-2010. MMWR Morb Mortal Wkly Rep. 2011;60(40):1377-1381.

74. Centers for Disease Control and Prevention (CDC). Prevalence of stroke-United States, 2006-2010. MMWR Morb Mortal Wkly Rep. 2012;61(20):379-382. 
75. Gold MR, Siegel JE, Russell LB, Weinstein MC, eds. CostEffectiveness in Health and Medicine. New York, NY: Oxford University Press; 1996.

76. Maciosek MV, Coffield AB, McGinnis JM, et al. Methods for priority setting among clinical preventive services. Am J Prev Med. 2001; 21(1):10-19.

77. Arias E. United States life tables, 2009. Natl Vital Stat Rep. 2014; 62(7):1-63.

78. Seshadri S, Beiser A, Kelly-Hayes $M$, et al. The lifetime risk of stroke: estimates from the Framingham Study. Stroke. 2006;37(2): 345-350.

79. Chow RD, Wankhedkar KP, Mete M. Patients' preferences for selection of endpoints in cardiovascular clinical trials. J Community Hosp Intern Med Perspect. 2014;4:4.

80. Neumann PJ, Cohen JT, Weinstein MC. Updating costeffectiveness - the curious resilience of the $\$ 50,000$-per-QALY threshold. N Engl J Med. 2014;371(9):796-797.

81. Coffield AB, Maciosek MV, McGinnis JM, et al. Priorities among recommended clinical preventive services. Am J Prev Med. 2001; 21(1):1-9.

82. Dehmer SP, Maciosek MV, Flottemesch TJ. Aspirin Use to Prevent Cardiovascular Disease and Colorectal Cancer: A Decision Analysis: Technical Report. Rockville, MD: Agency for HealthcareResearch and Quality; 2015. AHRQ Publication No. 15-05229-EF-1

83. Dehmer SP, Maciosek MV, Flottemesch TJ, LaFrance AB, Whitlock EP. Aspirin for the primary prevention of cardiovascular disease and colorectal cancer: a decision analysis for the U.S. Preventive Services Task Force. Ann Intern Med. 2016;164(12):777-786.

84. Kahn R, Robertson RM, Smith R, Eddy D. The impact of prevention on reducing the burden of cardiovascular disease. Circulation. 2008;118(5):576-585.

85. Farley TA, Dalal MA, Mostashari F, Frieden TR. Deaths preventable in the U.S. by improvements in use of clinical preventive services. Am J Prev Med. 2010;38(6):600-609.

86. Homer J, Wile K, Yarnoff B, et al. Using simulation to compare established and emerging interventions to reduce cardiovascular disease risk in the United States. Prev Chronic Dis. 2014;11:E195.

87. Kottke TE, Faith DA, Jordan CO, Pronk NP, Thomas RJ, Capewell $S$. The comparative effectiveness of heart disease prevention and treatment strategies. Am J Prev Med. 2009;36(1):82-88.

88. Pletcher MJ, Lazar L, Bibbins-Domingo K, et al. Comparing impact and cost-effectiveness of primary prevention strategies for lipidlowering. Ann Intern Med. 2009;150(4):243-254.

89. Brandle M, Davidson MB, Schriger DL, Lorber B, Herman WH. Cost effectiveness of statin therapy for the primary prevention of major coronary events in individuals with type 2 diabetes. Diabetes Care. 2003;26(6):1796-1801.

90. Hirsch G, Homer J, Trogdon J, Wile K, Orenstein D. Using simulation to compare 4 categories of intervention for reducing cardiovascular disease risks. Am J Public Health. 2014;104(7):1187-1195.

91. Kok L, Engelfriet $P$, Jacobs-van der Bruggen MA, Hoogenveen RT, Boshuizen HC, Verschuren MW. The cost-effectiveness of implementing a new guideline for cardiovascular risk management in primary care in the Netherlands. Eur J Cardiovasc Prev Rehabil. 2009;16(3):371-376.

92. Cuzick J, Thorat MA, Bosetti C, et al. Estimates of benefits and harms of prophylactic use of aspirin in the general population. Ann Oncol. 2015;26(1):47-57.

93. Lim SS, Vos T, Flaxman AD, et al. A comparative risk assessment of burden of disease and injury attributable to 67 risk factors and risk factor clusters in 21 regions, 1990-2010: a systematic analysis for the Global Burden of Disease Study 2010. [published correction appears in Lancet. 2013;381(9867):628]. Lancet. 2012;380(9859): 2224-2260.
94. Gunning-Schepers L. The health benefits of prevention: a simulation approach. Health Policy. 1989;12(1-2):1-255.

95. Newman J, Grobman WA, Greenland P. Combination polypharmacy for cardiovascular disease prevention in men: a decision analysis and cost-effectiveness model. Prev Cardiol. 2008;11(1):36-41.

96. Pignone M, Earnshaw S, Pletcher MJ, Tice JA. Aspirin for the primary prevention of cardiovascular disease in women: a cost-utility analysis. Arch Intern Med. 2007;167(3):290-295.

97. Earnshaw SR, Scheiman J, Fendrick AM, McDade C, Pignone M. Cost-utility of aspirin and proton pump inhibitors for primary prevention. Arch Intern Med. 2011;171(3):218-225.

98. Greving JP, Buskens E, Koffijberg H, Algra A. Cost-effectiveness of aspirin treatment in the primary prevention of cardiovascular disease events in subgroups based on age, gender, and varying cardiovascular risk. Circulation. 2008;117(22):2875-2883.

99. Pignone M, Earnshaw S, Tice JA, Pletcher MJ. Aspirin, statins, or both drugs for the primary prevention of coronary heart disease events in men: a cost-utility analysis. Ann Intern Med. 2006;144(5): 326-336.

100. Littenberg B, Garber AM, Sox HCJ. Screening for hypertension. Ann Intern Med. 1990;112(3):192-202.

101. Gaziano TA, Steyn K, Cohen DJ, Weinstein MC, Opie LH. Costeffectiveness analysis of hypertension guidelines in South Africa: absolute risk versus blood pressure level. Circulation. 2005;112(23): 3569-3576.

102. Mar J, Rodríguez-Artalejo F. Which is more important for the efficiency of hypertension treatment: hypertension stage, type of drug or therapeutic compliance? J Hypertens. 2001;19(1):149-155.

103. Ward S, Lloyd Jones M, Pandor A, et al. A systematic review and economic evaluation of statins for the prevention of coronary events. [iii-iv.]. Health Technol Assess. 2007;11(14):1-160, iii-iv.

104. Bennett K, Kabir Z, Barry M, et al. Cost-effectiveness of treatments reducing coronary heart disease mortality in Ireland, 2000 to 2010. Value Health. 2009;12(1):10-15.

105. Hay JW, Sterling KL. Cost effectiveness of treating low HDLcholesterol in the primary prevention of coronary heart disease. Pharmacoeconomics. 2005;23(2):133-141.

106. Gaziano TA, Opie LH, Weinstein MC. Cardiovascular disease prevention with a multidrug regimen in the developing world: a costeffectiveness analysis. Lancet. 2006;368(9536):679-686.

107. Pignone M, Earnshaw S, McDade C, Pletcher MJ. Effect of including cancer mortality on the cost-effectiveness of aspirin for primary prevention in men. J Gen Intern Med. 2013;28(11):1483-1491.

108. Reynolds TM, Mardani A, Twomey PJ, Wierzbickid AS. Targeted versus global approaches to the management of hypercholesterolaemia. J R Soc Promot Health. 2008;128(5):248-254.

109. Nagata-Kobayashi S, Shimbo T, Matsui K, Fukui T. Costeffectiveness of pravastatin for primary prevention of coronary artery disease in Japan. Int J Cardiol. 2005;104(2):213-223.

110. Siu AL; U.S. Preventive Services Task Force. Screening for high blood pressure in adults: U.S. Preventive Services Task Force recommendation statement. Ann Intern Med. 2015;163(10):778-786.

111. Krakoff LR. Cost-effectiveness of ambulatory blood pressure: a reanalysis. Hypertension. 2006;47(1):29-34.

112. Yarows SA, Khoury S, Sowers JR. Cost effectiveness of 24-hour ambulatory blood pressure monitoring in evaluation and treatment of essential hypertension. Am J Hypertens. 1994;7(5):464-468.

113. Stone NJ, Robinson JG, Lichtenstein AH, et al; American College of Cardiology/American Heart Association Task Force on Practice Guidelines. 2013 ACC/AHA guideline on the treatment of blood cholesterol to reduce atherosclerotic cardiovascular risk in adults: a report of the American College of Cardiology/American Heart Association Task Force on Practice Guidelines. Circulation. 2014; $129(25)($ Suppl 2):S1-S45. 
114. James PA, Oparil S, Carter BL, et al. 2014 evidence-based guideline for the management of high blood pressure in adults: report from the panel members appointed to the Eighth Joint National Committee (JNC 8). JAMA. 2014;311(5):507-520.

115. Wierzbicki AS, Hardman TC, Viljoen A. Inhibition of pro-protein convertase subtilisin kexin 9 [corrected] (PCSK-9) as a treatment for hyperlipidaemia. Expert Opin Investig Drugs. 2012;21(5):667-676.

116. Robinson JG, Heistad DD, Fox KA. Atherosclerosis stabilization with PCSK-9 inhibition: An evolving concept for cardiovascular prevention. Atherosclerosis. 2015;243(2):593-597.

117. Nelson M, Reid C, Beilin L, et al. Rationale for a trial of low-dose aspirin for the primary prevention of major adverse cardiovascular events and vascular dementia in the elderly: Aspirin in Reducing Events in the Elderly (ASPREE). Drugs Aging. 2003;20(12):897-903.

118. De Berardis G, Sacco M, Evangelista V, et al; ACCEPT-D Study Group. Aspirin and Simvastatin Combination for Cardiovascular Events Prevention Trial in Diabetes (ACCEPT-D): design of a randomized study of the efficacy of low-dose aspirin in the prevention of cardiovascular events in subjects with diabetes mellitus treated with statins. Trials. 2007;8:21.

119. Selak V, Elley CR, Crengle S, et al. IMProving Adherence using Combination Therapy (IMPACT): design and protocol of a randomised controlled trial in primary care. Contemp Clin Trials. 2011; 32(6):909-915.

120. Bayer. A study to assess the efficacy and safety of enteric-coated acetylsalicylic acid in patients with moderate risk of cardiovascular disease (ARRIVE). Identifier NCT00501059. ClincialTrials.gov. http://clinicaltrials.gov/show/NCT00501059. Published Jul 2007. Updated Sep 30, 2016. Accessed Nov 10, 2015.
121. Fox JB, Shaw FE. Receipt of selected clinical preventive services by adults - United States, 2011-2012. MMWR Morb Mortal Wkly Rep. 2015;64(27):738-742.

122. Valderrama AL, Gillespie C, King SC, George MG, Hong Y, Gregg $\mathrm{E}$; Centers for Disease Control and Prevention (CDC). Vital signs: awareness and treatment of uncontrolled hypertension among adults-United States, 2003-2010. MMWR Morb Mortal Wkly Rep. 2012;61:703-709.

123. Fang J, Yang Q, Ayala C, Loustalot F. Disparities in access to care among US adults with self-reported hypertension. Am J Hypertens. 2014;27(11):1377-1386.

124. Brown DW, Giles WH, Greenlund KJ, Croft JB. Disparities in cholesterol screening: falling short of a national health objective. Prev Med. 2001;33(6):517-522.

125. Abdus S, Mistry KB, Selden TM. Racial and ethnic disparities in services and the Patient Protection and Affordable Care Act. Am J Public Health. 2015;105(Suppl 5):S668-S675.

126. Adepoju OE, Preston MA, Gonzales G. Health dare disparities in the post-Affordable Care Act Era. Am J Public Health. 2015; 105(Suppl 5):S665-S667.

127. McMorrow S, Long SK, Kenney GM, Anderson N. Uninsurance disparities have narrowed for black and Hispanic adults under the Affordable Care Act. Health Aff (Millwood). 2015;34(10):1774-1778.

128. Taksler GB, Keshner M, Fagerlin A, Hajizadeh N, Braithwaite RS. Personalized estimates of benefit from preventive care guidelines: a proof of concept. Ann Intern Med. 2013;159(3):161-168.

\section{CHANGE-OF-ADDRESS FORM \\ FAMAILY MEDICINE}

Please complete this form and mail to the following address or fax to Annals Circulation at 913-906-6080:

Annals of Family Medicine, Circulation Department, 11400 Tomahawk Creek Pkwy, Leawood, KS 66211-2680

Check if member of sponsoring organization:

$$
\begin{aligned}
& \square \text { AAFP } \square \text { ABFM } \square \text { STFM } \square \text { ADFM } \\
& \square \text { AFMRD } \square \text { NAPCRG } \square \text { CFPC }
\end{aligned}
$$

ID number from label on your journal cover

OLD Information (Please print.)

\begin{tabular}{ll}
\hline Name \\
\hline Company (if applicable) \\
\hline Address (Street plus Apt or Ste) \\
\hline City & Postal Code (9-digit ZIP for US) \\
\hline Country & Fax \\
\hline Telephone & \\
\hline E-Mail &
\end{tabular}

NEW Information (Please print.)

\begin{tabular}{lc}
\hline Name \\
\hline Company (if applicable) \\
\hline Address (Street plus Apt or Ste) \\
\hline City & Postal Code (9-digit ZIP for US) \\
\hline Country & Fax \\
\hline Telephone & \\
\hline E-Mail &
\end{tabular}

